\title{
Extremely atypical thrombus coating the left atrium and left atrial appendage
}

\author{
Andreia Fernandes, Joana Trigo, Gisela Costa, Joao Pais
}

Hospital Geral, Centro Hospitalar e Universitário de Coimbra, Coimbra, Portugal

\section{Correspondence to} Dr Andreia Fernandes, andreiafvf@gmail.com

\section{DESCRIPTION}

A 57-year-old female patient presented to our emergency department with irregular palpitations for more than $48 \mathrm{~h}$. She had a history of hypothyroidism on treatment without any other cardiovascular risk factors. An ECG performed at admission revealed atrial fibrillation with rapid ventricular response. She was referred to our echocardiography laboratory for study. The transthoracic echocardiogram demonstrated a structurally normal heart. With a goal of electrical cardioversion, the patient underwent transesophageal echocardiogram (TEE), which revealed a $4 \mathrm{~mm}$ image of medium echogenicity, coating the entire left atrium and left atrial appendage (figure $1 \mathrm{~A}-\mathrm{C}$ ).

Considering the clinical context, a rather atypical left atrial thrombus was considered the most likely diagnosis and the patient was put on oral anticoagulation with vitamin $\mathrm{K}$ antagonist. Two months later, a novel TEE was performed and the thrombus had partially disappeared (figure 2). Thrombophilia was subsequently excluded.

Thrombus formation in patients with nonvalvular AF results from stagnant blood in the

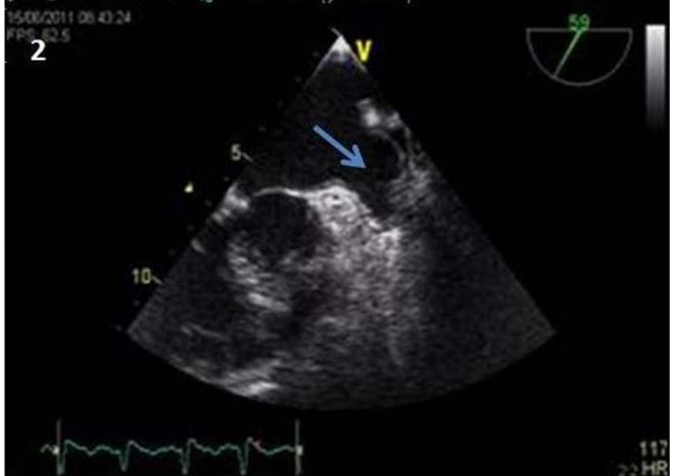

Figure 2 Control transesophageal echocardiogram revealing the thrombus disappearance.

atria, ${ }^{1}$ combined with other physiological derangements such as progressive atrial dilation and abnormal platelet activation and changes in coagulation factors, contributing to an increased propensity for blood clot formation. This particular shape of thrombus coating the entire left atrium and left atrial appendage has never been reported before,

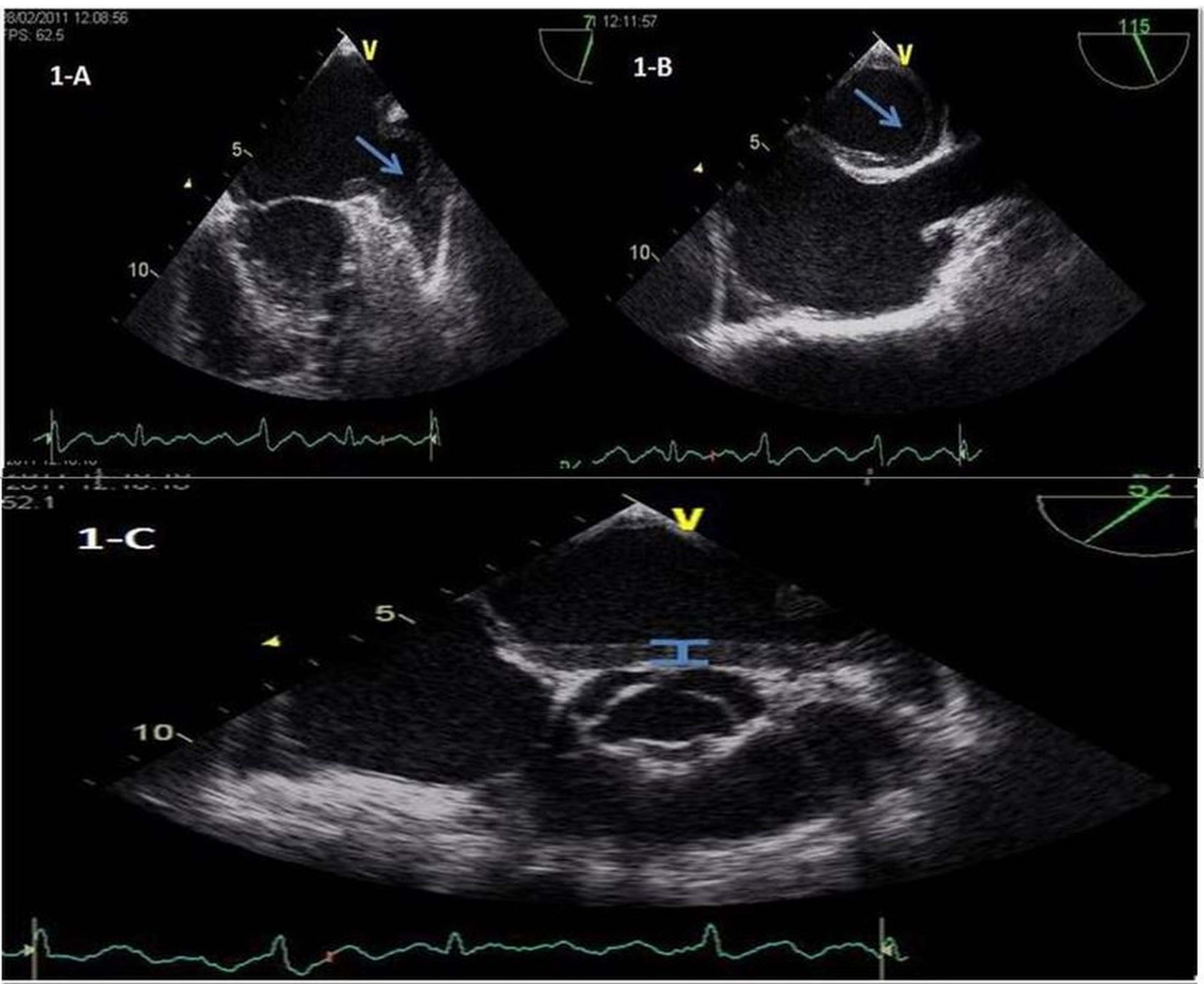

Figure 1 (A-C) Image of medium echogenicity coating the entire left atrium and left atrial appendage (arrows). 
and thus represents an extremely rare form of presentation. Physicians should be aware of the potential high variability of thrombus shape and location.

\section{Learning points}

- Thrombus formation in patients with non-valvular atrial fibrillation results from stagnant blood in the atria, combined with other physiological derangements such as progressive atrial dilation and abnormal platelet activation and changes in coagulation factors.

- Physicians should be aware of the potential high variability of thrombus shape and location.

- Treatment with oral anticoagulant is extremely important in order to prevent embolisation.
Acknowledgements The authors would like to thank Dr Providencia and Sergio Barra for help in the preparation of the manuscript.

Contributors AF was involved in writing the manuscript. JP reviewed the manuscript. JT and GC performed the ECG of the patient.

Competing interests None.

Patient consent Obtained.

Provenance and peer review Not commissioned; externally peer reviewed.

\section{REFERENCE}

1 Hakan Ay, Arsava EM, Lale $S$, et al. Hyperhomocysteinemia is associated with the presence of left atrial thrombus in stroke patients with nonvalvular atrial fibrillation. Stroke 2003;34:909-12.

Copyright 2014 BMJ Publishing Group. All rights reserved. For permission to reuse any of this content visit http://group.bmj.com/group/rights-licensing/permissions.

BMJ Case Report Fellows may re-use this article for personal use and teaching without any further permission.

Become a Fellow of BMJ Case Reports today and you can:

- Submit as many cases as you like

- Enjoy fast sympathetic peer review and rapid publication of accepted articles

- Access all the published articles

- Re-use any of the published material for personal use and teaching without further permission

For information on Institutional Fellowships contact consortiasales@bmjgroup.com

Visit casereports.bmj.com for more articles like this and to become a Fellow 